\title{
Evaluation of the Hazard Perception Skills of Young Drivers
}

\author{
Hannes Sappl ${ }^{1 *}$ and Tibor Kubjatko ${ }^{1}$ \\ ${ }^{1}$ University of Žilina, Institute for Forensic Research and Education, Ulica 1. mája 32, 01026 \\ Žilina, Slovakia; Email: sappl@unfallrekonstruktion.at, tkubjatko@gmail.com
}

*Corresponding Author: Hannes Sappl

Received: 14 October 2020; Revised: 3 November 2020; Accepted: 22 February 2021; Published: 31 May 2021

Abstract: The aim of this study is to collate valuable information about the hazard perception process of (young) drivers and to evaluate their hazard perception skills. For this, an eye-tracking system was used to record the visual behaviour of drivers. In addition, a system based on a data logger and sensors was developed to capture and log the relevant data from the vehicle. By tapping into the vehicle's CAN bus (Controller Area Network), the needed parameters (e.g. position of accelerator, brake, and clutch pedal, as well as the steering wheel angle) were acquired through the reverse engineering of the vehicle's CAN stream. All the captured data was subsequently synchronized and overlaid in the eye-tracking video. The complete system, i.e. data-logger and sensors, was consistently integrated into a driving school car. Due to the fact that all the data was captured in real-time whilst driving in traffic, every analysed situation can be considered unique and therefore cannot be compared to other situations. The results of the study revealed that only in $18 \%$ of the analysed situations, the hazard-perception skills were adequate or the same as they were taught at the driving school just a few months previous. Confronted by the videos of their lessons, the participating drivers adjusted their self-assessment scores for their driving skills downwards by around $25 \%$ on average.

Keywords: Hazard perception, eye tracking, real-time traffic, CAN bus, reverse engineering

\section{Introduction}

In countries like Great Britain and the Netherlands "hazard perception" has been an important topic in driver education and the driving test for many years. In Great Britain for example, the Hazard Perception Test (HPT) is part of the theory test, whereby traffic video clips from the driver's point of view are shown to the participant. Each video clip contains one or two developing hazards. A developing hazard is a traffic situation that requires the driver to act, such as changing speed or 
direction [1]. The participant must prove that they have spotted the developing hazard by clicking on their mouse. The earlier a developing hazard is spotted, the higher the score they receive, with a maximum of 5 points awarded [2]. In Austria and Germany for example, "hazard perception" only plays a small and unimportant role in the process of driver education. In Austria, the German word for hazard perception (Gefahrenwahrnehmung) only appears 4 times in the relevant legislation and curricula for obtaining a driving licence [3]. On the other hand, studies show that hazard perception abilities are a central part of someone's driving skills and are closely connected to the risk of having an accident [4].

The aim of this study is to collate valuable information about the hazard perception process of (young) drivers and to evaluate how good their hazard perception skills actually, and how they perceive their own hazard perception skills before and after their debriefing.

Obtaining information about hazard perception is usually either done by showing a video to a candidate who has to push a button when they recognise a (potential) hazard, or in front of a driving simulator in which the candidates are equipped with an eye-tracking system and all the needed information is collected by the simulator [5].

The basis of this study was to evaluate hazard perception by capturing data in a real car and in real-time whilst driving in traffic to get as realistic results as possible. The disadvantage of this methodology is that every captured situation was unique and could not be compared to other situations. It was therefore not possible to conduct a statistical evaluation. The results are therefore described qualitatively.

\section{Methods}

\subsection{Experimental Setup}

For this study, the Viewpointsystem eye-tracking system was used to record the visual behaviour of the drivers. In the 25-fps output video of the eye-tracking system, the driver's field of vision was overlaid with their point of focus. As shown in Figure 1, the inner circle represents the $2^{\circ}$ foveal (detailed recognition) field of vision, and the outer circle the $10^{\circ}$ parafoveal (perception of colours, shapes and contrast) field of vision. In addition, a system based on a data logger and sensors was developed to capture and log the relevant data from the vehicle. To log the accelerations (both lateral and longitudinal) and the GPS position, the well-known DL1 (Data Logger) from Race Technology was used and mounted onto a $10 \mathrm{~kg}$ steel plate with levelling screws to reduce the influence of oscillatory instability. The unit was subsequently placed horizontally behind the instructor's/co-driver's seat [6].

By tapping into the vehicles CAN bus, the rest of the needed parameters were acquired through reverse engineering of the vehicles CAN stream. 
To eliminate the gravitational coupling due to the acceleration-dependent movement of the car, and to get the real values of lateral and longitudinal acceleration, the car was also equipped with 4 ultrasonic sensors attached to the corners of the chassis, each measuring the distance to the ground. The measured distances enabled the pitch and roll angle to be calculated, as well as the subtraction of the gravity-based accelerations from the measured accelerations [7].

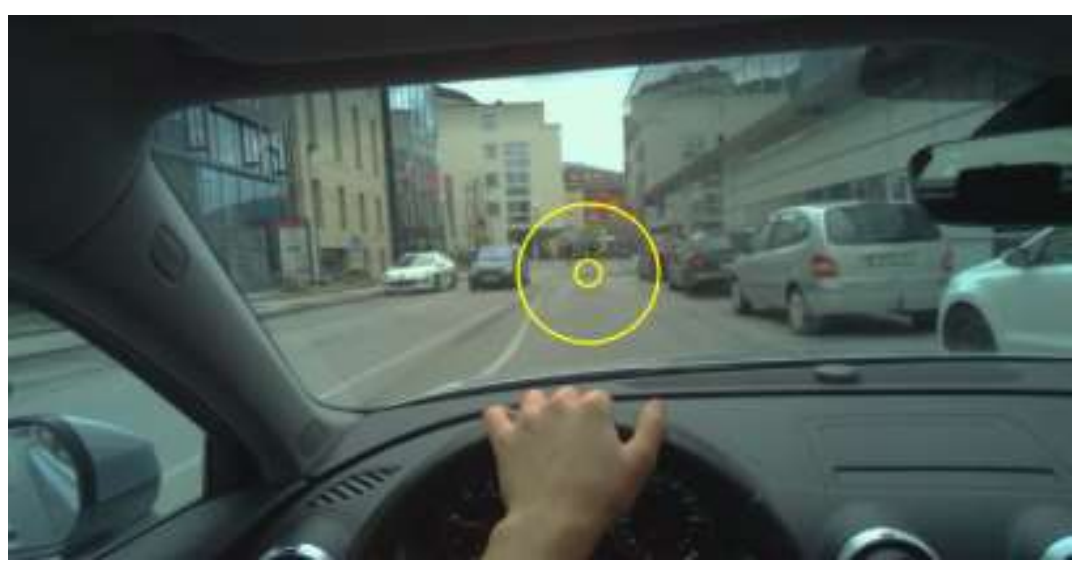

Fig. 1 Foveal and parafoveal fields of vision. Source: authors

To capture all the signals and pass them on to the datalogger, as well as to provide the needed voltage to the sensors, an input/output (I/O) board was developed and mounted to the steel plate next to the DL1 (see Figure 2).

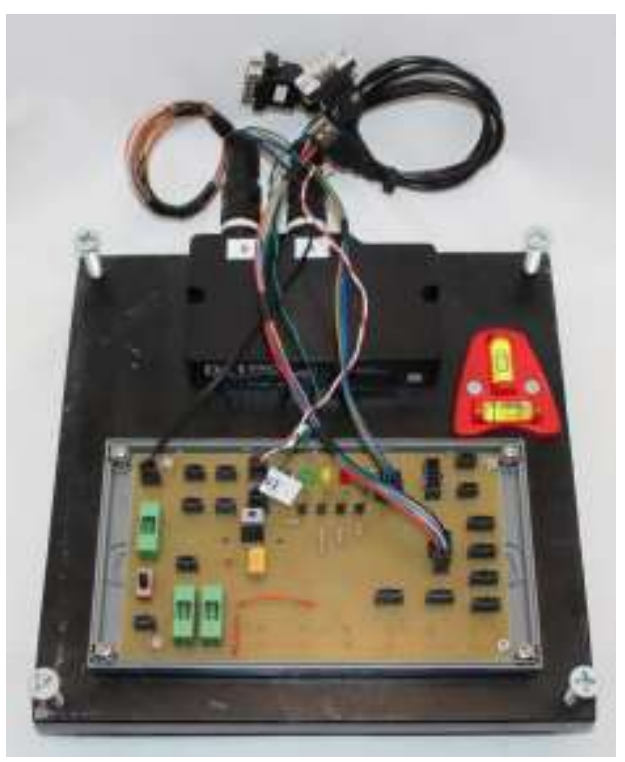

Fig. 2 Datalogger and I/O board. Source: authors

To control the system from the driver's or instructor's/co-driver's seat, a wired remote was also installed and connected to the I/O board. This provided the driver or instructor with all the required LEDs and buttons accordingly.

The following data was captured by the sensors or via the CAN bus and logged or calculated by the datalogger in real-time [8]:

- Accelerations (both longitudinal and lateral)

- $\quad$ Pitch and roll angle 
- GPS position

- Position of accelerator, brake and clutch pedals

- $\quad$ Steering wheel angle

- $\quad$ Steering wheel angular speed

- $\quad$ Speed (CAN and GPS)

- $\quad$ RPM

- Active gear

An LED was used to synchronize the video from the eye-tracking system and the logged data. By pressing a button on the remote, an LED lit up in the driver's field of vision. The act of pressing the button was also logged by the data logger [9]. The final result: all the captured data was synchronized and overlaid for the driving situation and time (Figure 3).

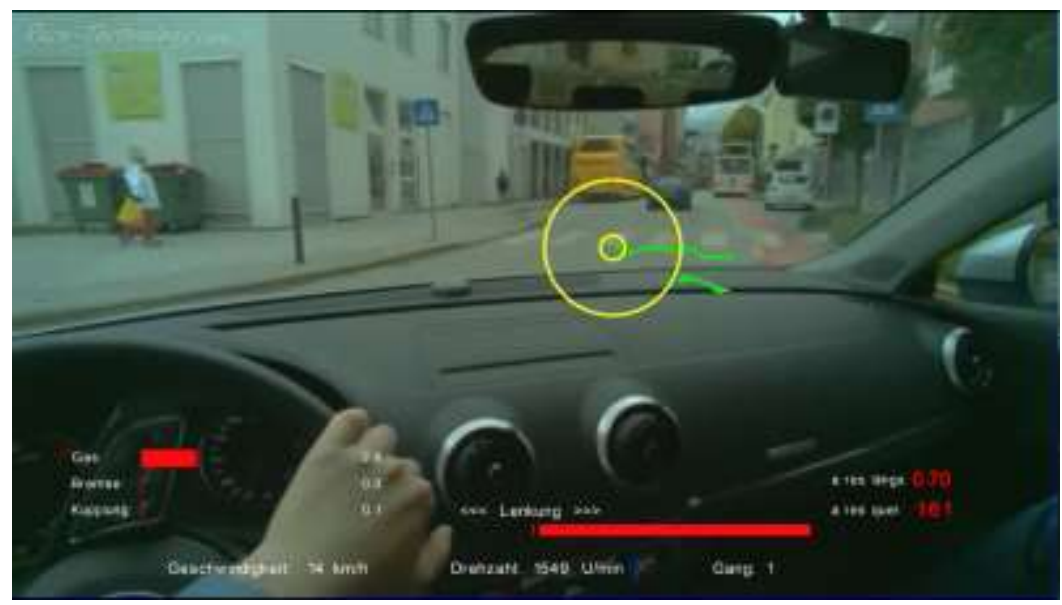

Fig. 3 Eye-tracking video overlaid with signals from the datalogger. Source: authors

To avoid deviations due to non- $100 \%$ consistent frame rates, the process of synchronization could be repeated as often as required [10]. The described system was able to measure:

- Recognition: when the (potential) hazard appears in the driver's foveal or parafoveal fields of vision.

- Decision: when the driver changes pedal positions, speed, or direction.

- Action: the strength of the driver's reaction (e.g. measured deceleration).

The complete system, i.e. datalogger and sensors, was consistently integrated into a driving school car (Audi A3 Sportback 1.6 TDI, $85 \mathrm{~kW}$, model year 2017) to perform the tests.

\subsection{Participating Drivers}

The participating drivers were young drivers who had passed their driving test between 3 and 15 months prior to the commencement of this study. The average age of the participants was 18 years, each with $15,100 \mathrm{~km}$ of self-driving experience on average. According to their self-assessment, the average score for their hazard perception skills was 8 out of 10 . After every lesson the recorded 
video was shown to the driver and the situations in which their hazard perception skills were considered inadequate were discussed. After their debriefing, the drivers were given the opportunity to reassess their hazard perception skills on the 10-point scale. In total, this study includes the driving lessons of 25 drivers. Per driver, two suitable situations involving pedestrians crossing or stepping in to the road were picked out and analysed. In the following section, three examples are given and described in detail.

\section{Results}

\subsection{First Example}

In the first video, a driver passes parked cars in a built up area at $29 \mathrm{~km} / \mathrm{h}$. As can be seen in Figure 4, a pedestrian standing between the cars comes into the driver's vision for the first time. At this point, the accelerator pedal position is at $16 \%$.

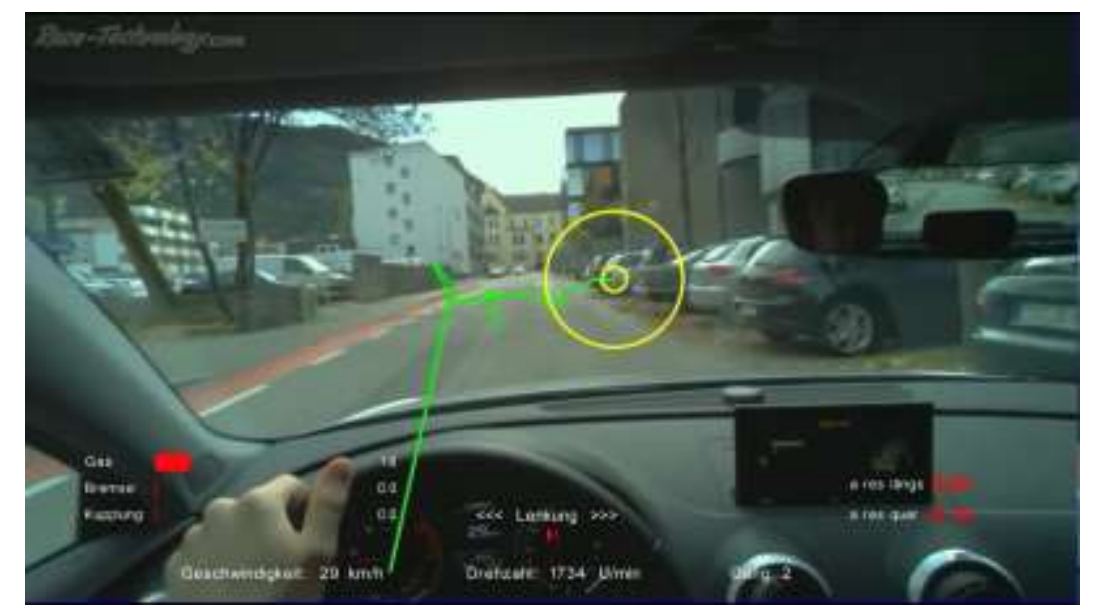

Fig. 4 Pedestrian in the driver's vision. Source: authors

9 frames later (between 360 and $440 \mathrm{~ms}$ ), as can be seen in Figure 5, the pedestrian is still in the driver's vision. However, the driver has now completely taken their foot off the accelerator pedal $(0 \%)$.

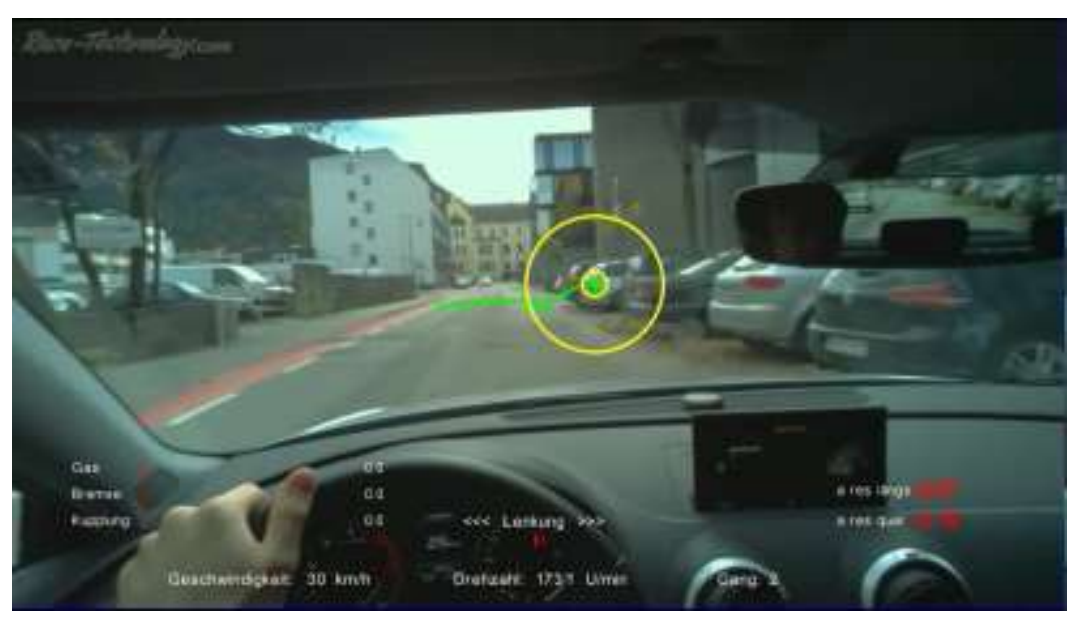

Fig. 5 Driver has taken foot completely off the accelerator pedal. Source: authors 
When it appears to be very clear that the pedestrian is looking at the car or driver, the driver starts to press the accelerator pedal again (2\%), while still watching the pedestrian's behaviour (see Figure 6).

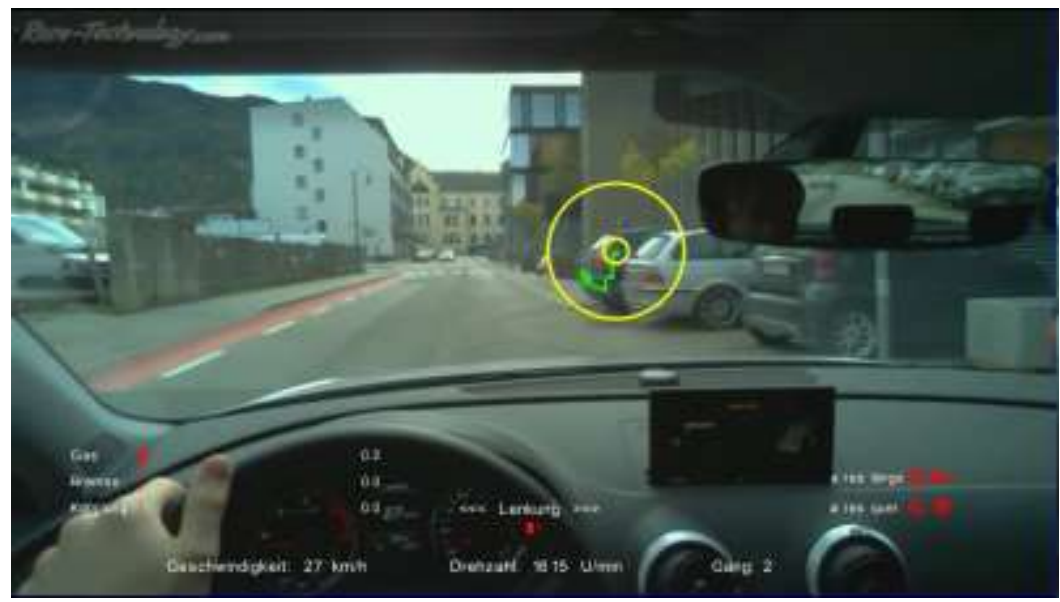

Fig. 6 Driver starts to accelerate again. Source: authors

As can been seen in Figure 7, when the car has almost come into line with the pedestrian's position at $25 \mathrm{~km} / \mathrm{h}$, the driver for the first time turns their focus away from the pedestrian and starts to accelerate again (12\% pedal position). This video shows that the driver, upon first noticing the pedestrian, immediately took their foot off the accelerator pedal and subsequently kept observing the pedestrian's behaviour. The pedestrian didn't have to take a step on to the road to trigger the driver's prompt reaction. Rather, the driver reacted by slightly reducing their speed in readiness to brake, which was ultimately not necessary.

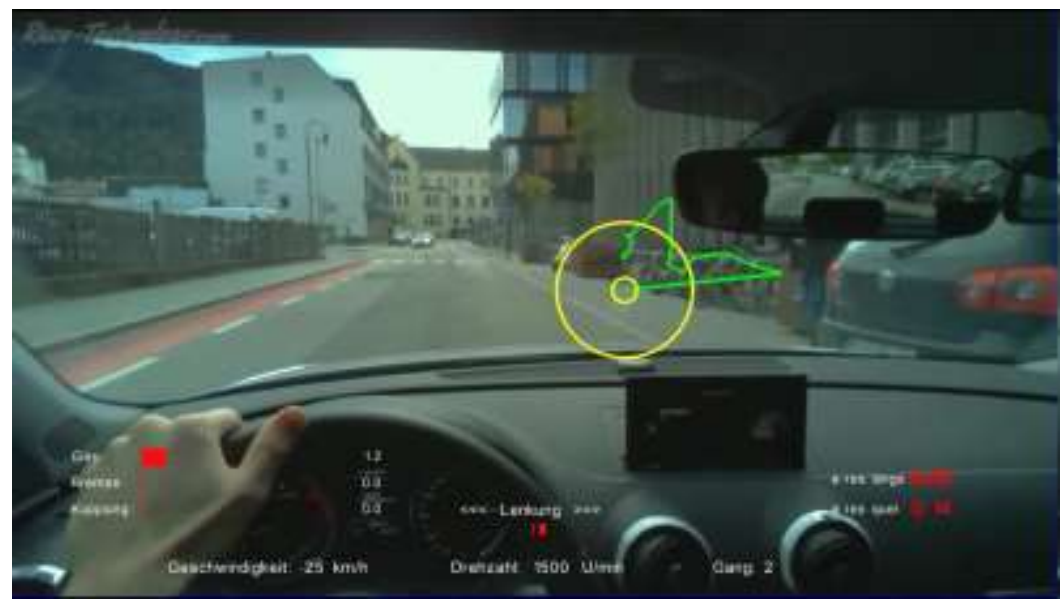

Fig. 7 Driver turns their focus away from the pedestrian. Source: authors

\subsection{Second Example}

In the second video, the driver is approaching a zebra crossing in a built up area - speed $17 \mathrm{~km} / \mathrm{h}$; accelerator pedal position 29\%; longitudinal acceleration $1.12 \mathrm{~m} / \mathrm{s}^{2}$. Up ahead, there are buses positioned on both sides of the street. In front of the bus on the left, the heads of pedestrians 
watching the oncoming traffic can clearly be seen. However, the driver is focused on the car in front of them (see Figure 8).

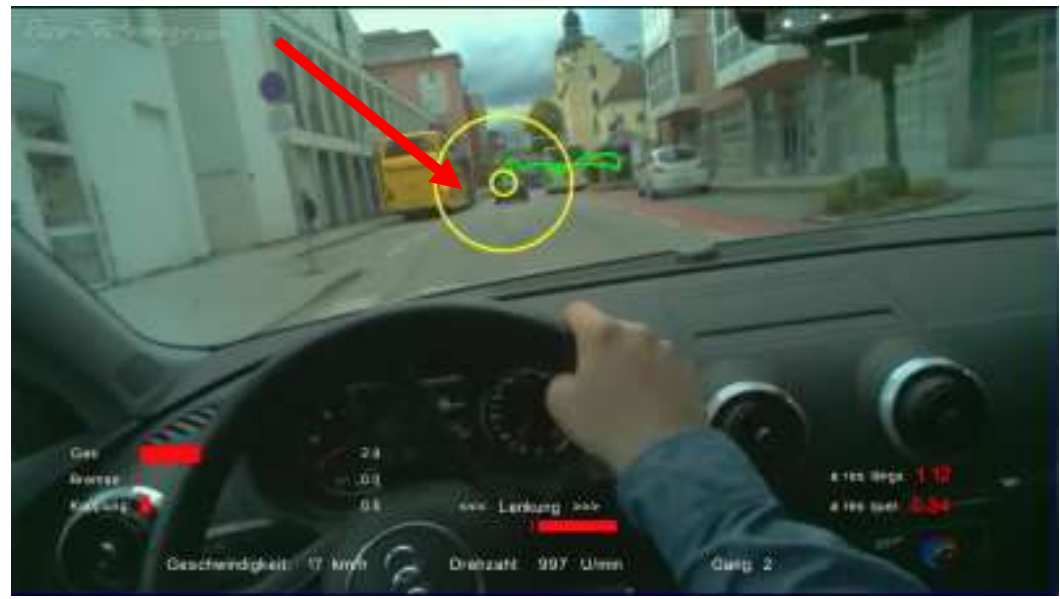

Fig. 8 Pedestrians heads in front of the bus. Source: authors

20 frames later, as can be seen in Figure 9, the bus on the right starts to indicate to the left. The pedestrians on the left are still watching the traffic and the driver is still focused on the car in front speed $20 \mathrm{~km} / \mathrm{h}$; accelerator pedal position $47 \%$; longitudinal acceleration $1.36 \mathrm{~m} / \mathrm{s}^{2}$. Only after the accelerator pedal position reaches $56 \%$, longitudinal acceleration $1.92 \mathrm{~m} / \mathrm{s}^{2}$, and speed $32 \mathrm{~km} / \mathrm{h}$, does the driver start to react by pressing the clutch to shift down to 3rd gear, whilst still focusing on the car in front of them. The bus on the right is still indicating and the complete upper bodies of the pedestrians on the left are visible behind the yellow bus (see Figure 10). As passing an indicating bus in a built up area is a traffic offence in Austria, the driving instructor intervenes to stop the car with maximum deceleration of $6.1 \mathrm{~m} / \mathrm{s}^{2}$.

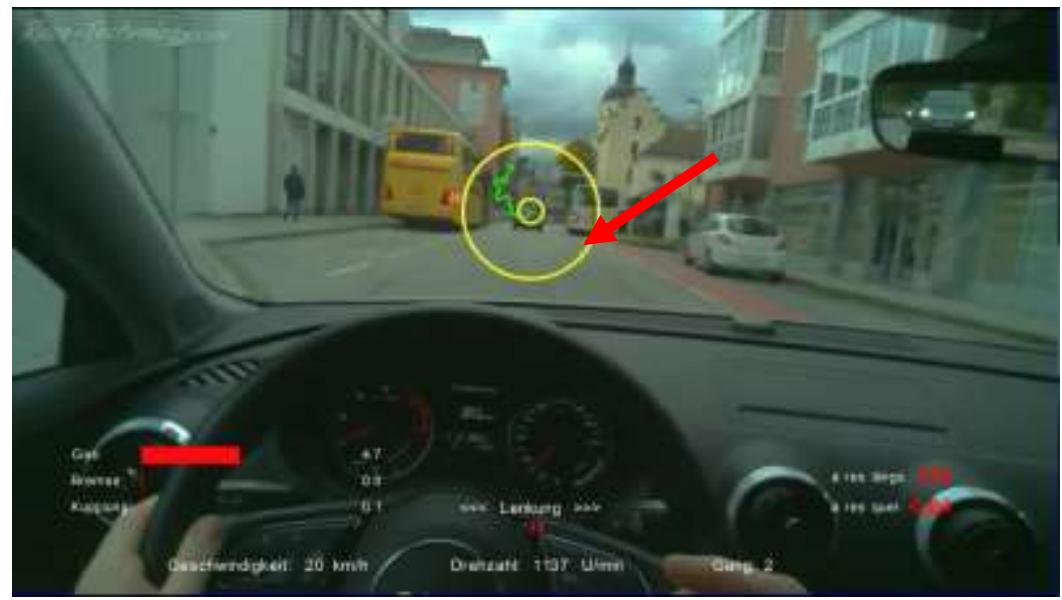

Fig. 9 Bus indicating to the left. Source: authors 


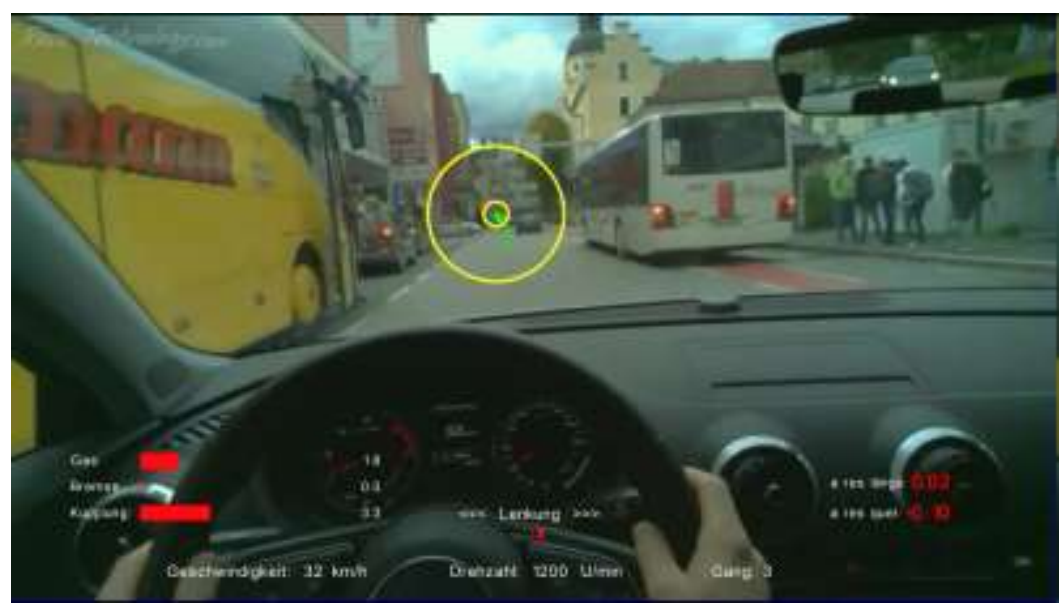

Fig. 10 Driving instructor intervenes to stop the car. Source: authors

The surprised driver now takes their focus off the car in front and starts looking around to find the reason for the driving instructor's intervention. 29 frames later, as can be seen in Figure 11, the driver focuses on the flashing indicator of the bus on the right. Seconds later, the driver also looks to the left where they can see the waiting pedestrians for the first time (see Figure 12). This video shows a situation in which the driver didn't recognize a hazardous situation at all and keeps on driving at an increasing speed.

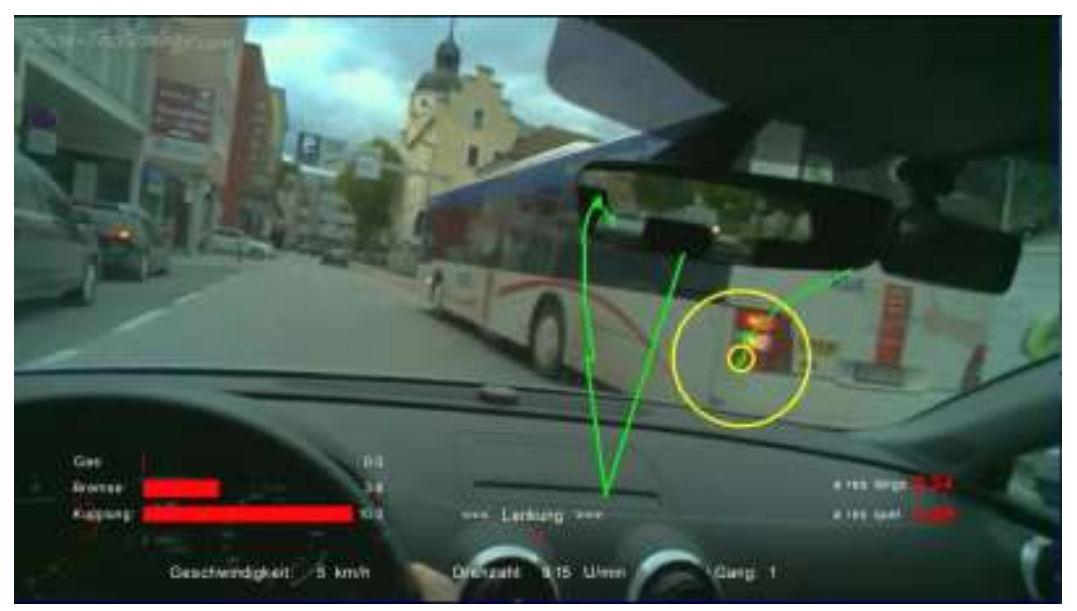

Fig. 11 Driver focuses on the flashing indicator for the first time. Source: authors

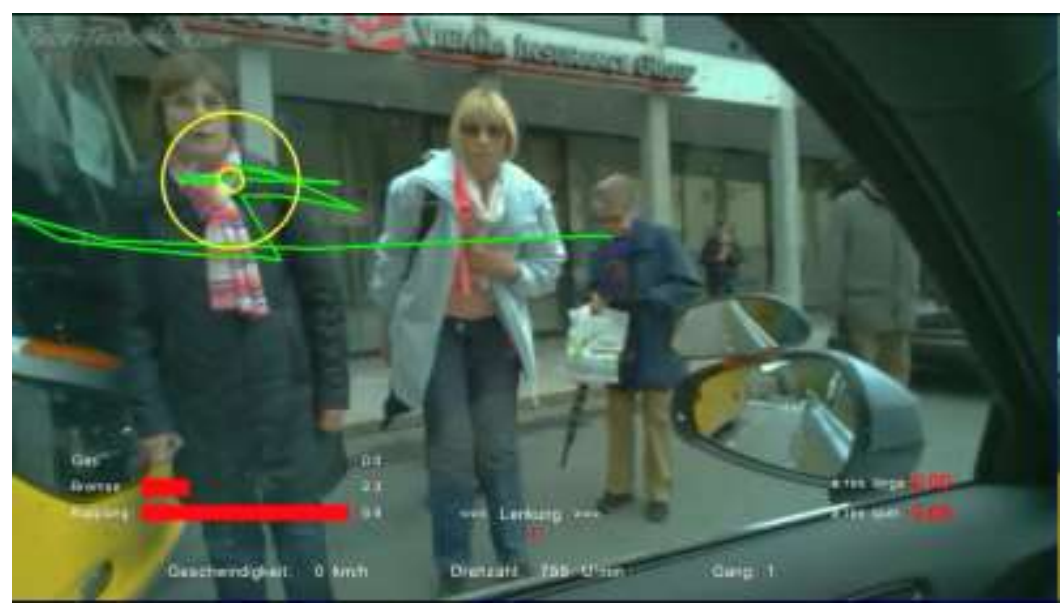

Fig. 12 Driver looks at the pedestrians for the first. Source: authors 


\subsection{Third Example}

In the third video, the driver is, once again, approaching a zebra crossing in a built up area at 27 $\mathrm{km} / \mathrm{h}$. The pedal positions are all $0 \%$ because the slightly downward sloping street maintains the car's momentum without the need for pressing the accelerator pedal. The driver's vision is focused on a building in front of them. However, on the right, two teenagers are approaching the zebra crossing (see Figure 13). 30 frames later, the driver still hasn't observed the pedestrians, whose upper bodies are now hidden by the rear-view mirror (see Figure 14). It is only when the driver looks in their rear-view mirror 14 frames later, that the legs of the pedestrians appear in the driver's parafoveal field of vision (see Figure 15), causing the driver to focus on them for the first time (see Figure 16). As the pedestrians' heads are hidden by the mirror, the driver is unable to see where the pedestrians are looking. Nevertheless, the driver doesn't change their pedal positions at all and keeps on driving at the same speed.

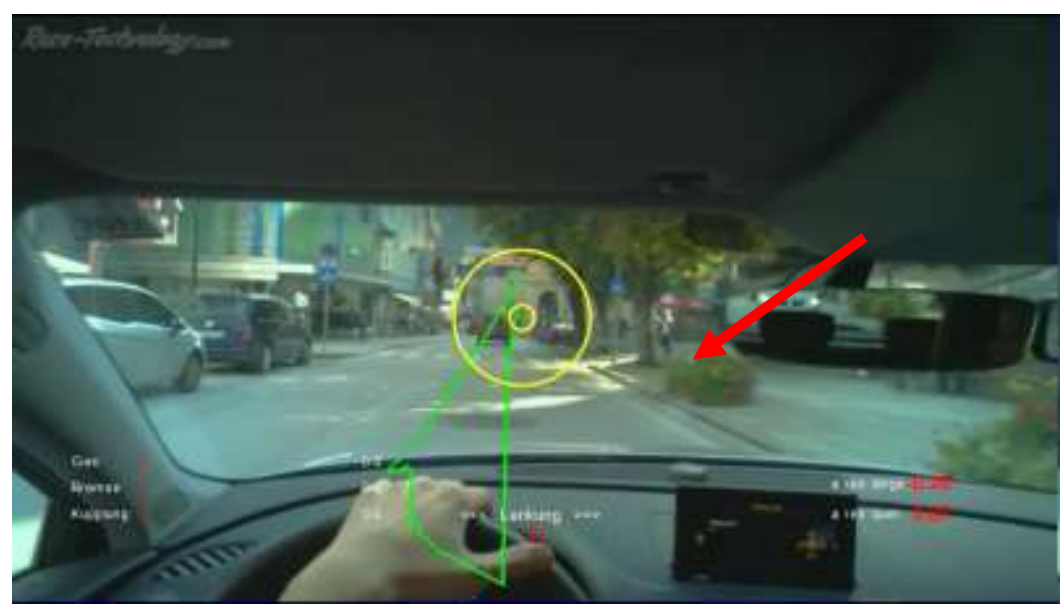

Fig. 13 Teenagers heading towards the zebra crossing. Source: authors

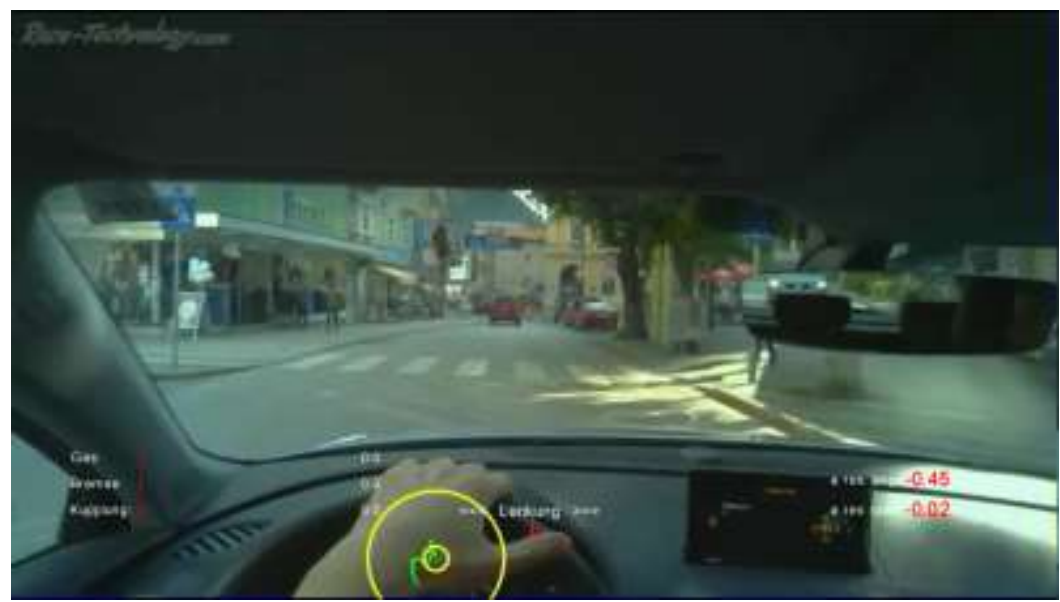

Fig. 14 Pedestrians hidden by the rear-view mirror. Source: authors 


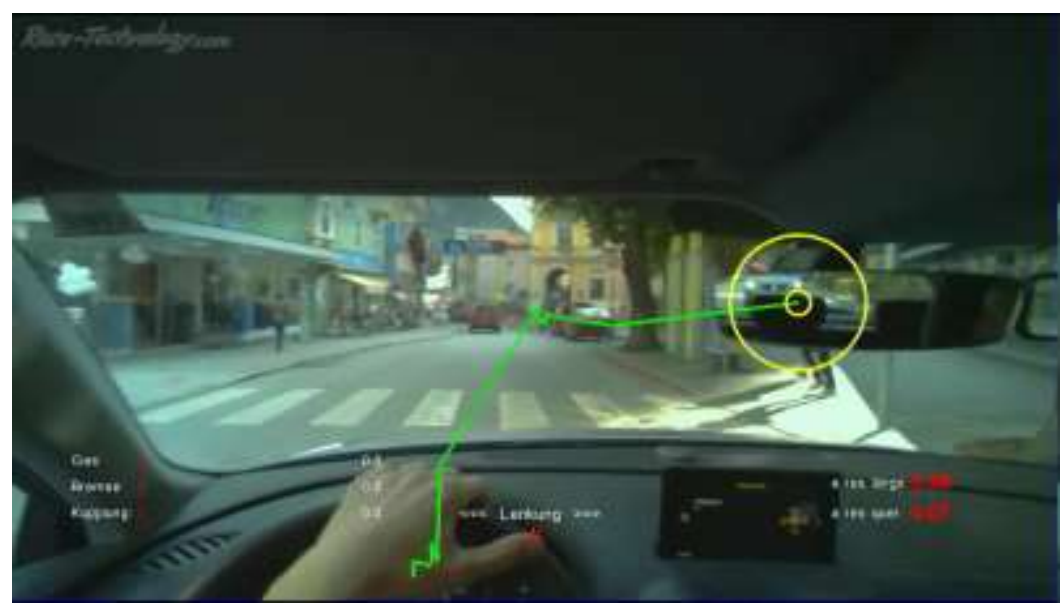

Fig. 15 Pedestrians become visible in the driver's parafoveal field of vision. Source: authors

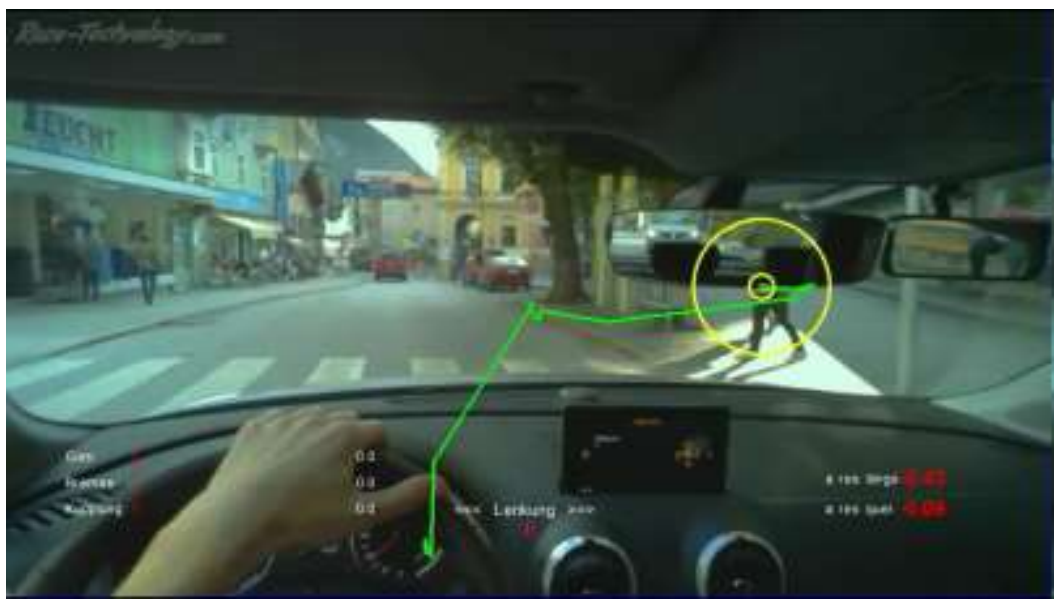

Fig. 16 Driver looks at the pedestrians for the first time. Source: authors

\subsection{Reassessment}

After watching the recorded videos following the driving lesson, all participating drivers admitted that there was at least one situation in which they were surprised or shocked at their own visual behaviour or about the fact that they had not recognised a potentially hazardous situation. Confronted by these videos, the participating drivers adjusted the self-assessment scores for their hazard perception abilities downwards from $8 / 10$ to $6 / 10$ points on average, a decrease of $25 \%$.

\section{Conclusion}

According to all 50 analysed situations of the 25 participating drivers, and according to the examples given, three different types of hazard perception can be identified (see Figure 17):

1. Drivers don't recognise a (potential) hazardous situation at all and keep driving at the same or at increasing speed (occurred in 29 situations). In a few cases, the car had to be stopped by the driving instructor to avoid a traffic offence or an accident.

2. Drivers see a (potential) hazard, but keep driving at the same speed and don't change their pedal positions (occurred in 12 situations). 
3. Drivers observe the situation attentively and decrease their accelerator pedal position or start to press on the brake pedal to slow down the car a little bit (occurred in 9 situations). When the situation becomes clearer (for example due to eye contact between the driver and the pedestrian(s)), and the driver is sufficiently convinced that the pedestrian will not take a step into the road, the driver increases the accelerator pedal position again and drives on.

In conclusion, in only $18 \%$ of the analysed situations were the hazard perception skills judged to be adequate or as taught at the driving school just a few months previous.

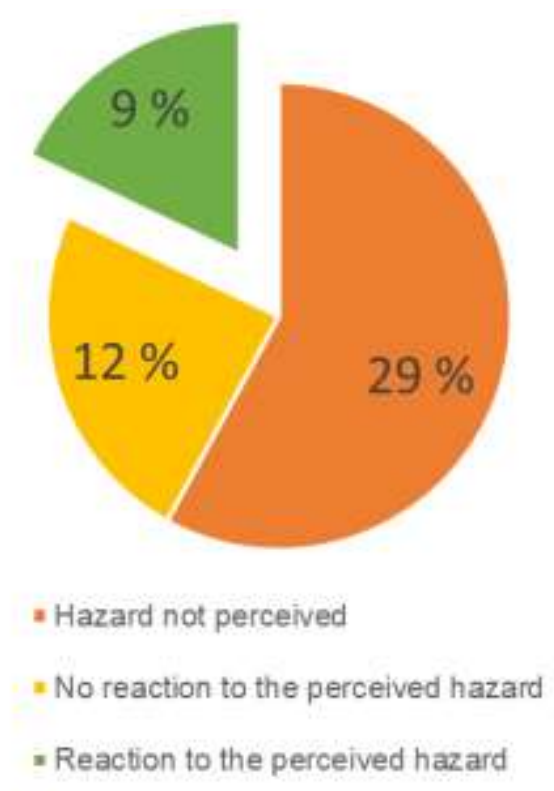

Fig. 17. Types of hazard perception. Source: authors

When a driver is in a similar situation to " 1 " above, and is informed of their error during, not after, the lesson, there is a noticeable improvement in behaviour when they are confronted with a similar situation during the same driving lesson.

Under " 3 " above, the driver is not effectively applying the traditional 2-step model of "reacting and braking fully", which is widely applied in the field of accident reconstruction. By reducing speed early, this type of driver adds an in-between step to the model, which makes their driving much safer. Using this model would require a new method for calculating accident avoidance.

\section{References}

[1] Dirnbach, I., Kolla, E., Ondruš, J. \& Kubjatko, T. (2020). Methodology designed to evaluate accidents at intersection crossings with respect to forensic purposes and transport sustainability. DOI: 10.3390/su12051972.

[2] Government Digital Service (GDS). Hazard perception test, Retrieved November 6, 2020, from https://www.gov.uk/theory-test/hazard-perception-test. 
[3] Federal Ministry for Digitization and Business Location, Federal Legal Information System search term „Hazard warning*“ (in German), Retrieved November 6, 2020, from https://www.ris.bka.gv.at/Ergebnis.wxe?Abfrage=Bundesnormen \&Kundmachungsorgan=\&In $\operatorname{dex}=\&$ Titel $=\&$ Gesetzesnummer $=\&$ VonArtikel $=\&$ BisArtikel $=\&$ VonParagraf $=\&$ BisParagraf $=$ $\&$ VonAnlage $=\&$ BisAnlage $=\&$ Typ $=\&$ Kundmachungsnummer $=\&$ Unterzeichnungsdatum $=\& \mathrm{~F}$ assungVom=09.11.2020 $\&$ VonInkrafttretedatum $=\&$ BisInkrafttretedatum $=\&$ VonAusserkrafttre tedatum $=\&$ BisAusserkrafttretedatum $=\&$ NormabschnittnummerKombination=Und $\&$ ImRisSeit VonDatum=\&ImRisSeitBisDatum $=\& I m R i s S e i t=$ Undefined $\&$ ResultPageSize $=100 \&$ Suchwort $\mathrm{e}=$ Gefahrenwahr $* \&$ Position $=1 \&$ SkipToDocumentPage $=$ true.

[4] Horswill, M.S. \& McKenna, F.P. (2004). Driver's hazard perception ability: Situation awareness on the road. ISBN 0754641988.

[5] Waard, D., Axelsson, A., Berglund, M., Peters, B. \& Weikert, C. (2010). Human factors as system view of human, technology and organization, Maastricht: Shaker Publishing. ISBN 978-9042303959.

[6] Nickel, M. \& Hugemann, W. (2003) Longitudinal and lateral accelerations in everyday traffic (in German). Retrieved December 10, 2020, from https://www.researchgate.net/publication/237485864_LANGS_UND_QUERBESCHLEUNIGUNGEN_IM_ALLTAGSVERKEHR.

[7] Kolla, E., Vertal, P., Fallast, K., Huber, G., Franz, G., Neuschmied, H., Thallinger, G. \& Krebs, F. (2019). Evaluation of SIMMARC: An Audiovisual System for the Detection of Near-Miss Accidents. DOI: 10.1007/978-3-030-38822-5_13.

[8] Ondruš, J. \& Kolla, E. (2017). Practical use of the braking attributes measurements results. DOI: $10.1051 /$ matecconf/201713400044.

[9] Kubjatko, T., Görtz, M., Macurová, L. \& Ballay, M. (2018). Synergy of forensic and security engineering in relation to the model of deformation energies on vehicles after traffic accidents. DOI: 10.14669/AM.VOL84.ART11.

[10] Böhm, K., Kubjatko, T., Paula, D. \& Schweiger, H-G. (2020). New developments on EDR (Event Data Recorder) for automated vehicles. DOI: 10.1515/eng-2020-0007. 